\title{
South African scientists urged to propose projects for future support
}

Johannesburg. A leading official of South Africa's new democratic government has appealed to the nation's scientists for help in developing its science and technology investment programme.

Bernie Faranoff, the official charged with South Africa's Reconstruction and Development Programme (RDP), said the government is ready to invest in science, but needs advice in picking the right areas.

Speaking at a conference held at the University of the Witwatersrand in Johannesburg and organized by the Royal Society of South Africa, Faranoff said that the RDP recognized the need to develop the human

\section{Nature ownership to change hands}

London. Macmillan Ltd, the privately owned British publishing group whose subsidiary, Macmillan Magazines Ltd, is the publisher of Nature, announced last week that the German publishing house, Verlagsgruppe Georg von Holtzbrinck, is to take a majority stake in the company.

Holtzbrinck, which was founded in 1971, has a range of publishing and media interests, including the US publishers Henry Holt, and Farrar Straus and Giroux. Its imprints include the academic publishing houses Spektrum Academischer in Germany and W.H. Freeman and Worth in the United States, and it is also the publisher of Scientific American.

Under an agreement between the two companies, Macmillan - which launched Nature in 1869 - will continue to operate independently, and a statement from the company says that no changes in the management or the organization of the business are planned other than those that will evolve through its continuing expansion.

The board of Macmillan, most of whose shares are held in trust for the Macmillan family, had previously considered a public flotation. But Nicholas Byam Shaw, its chairman, said that this had been rejected "in favour of an alliance with a publisher whose philosophy of investment matches the long-term nature of Macmillan's own culture and tradition".

Sir John Maddox, the editor of Nature, said that the welcomed the move as "probably the best for Nature" of the various options that had been under consideration by the board. "Holtzbrinck is a company with a long-term view of the health and welfare of magazines, which it has already shown in its treatment of other titles," he said. resources needed by science and technology.

But he added that "it is up to the universities and scientists themselves to come up with suggestions on how they can contribute to development in South Africa”. Government spending on research and development (R\&D) in next year's budget, he said, would be determined by the RDP office in line with the plan's goals, along with budgets for all government departments.

Faranoff, a radio-astronomer by training who spent nearly two decades working in the trade union movement, has in the past said he believed spending on R\&D in South Africa should be "drastically increased". $\mathrm{He}$ told the meeting, which was opened by Ben Ngubane, Minister of Arts, Culture, Science and Technology, that the national development plan being drawn up would support good proposals for developing science and technology in South Africa. But, he added, it was important that the proposals arose from a partnership of scientists in universities, government departments and industry.

Acknowledging the relatively small sums allocated for science in this year's budget allocations to individual research councils have been largely calculated by awarding small, if varying, percentage increases to each (see Nature 374, 487; 1995) - Faranoff promised that next year's budget would be "zero-based", with funds allocated in accordance with the goals of the RDP.

This would be the first phase of a multiyear funding programme, he said, whose length is yet to be decided by Cabinet. Such an approach, he explained, would lend stability to the system by ensuring funding for the whole duration of research programmes - provided that agreed performance criteria were met.

The government is expected to complete by August an audit of its present allocation and use of all state funds, including those handed out for research. The object of the exercise is to assess the extent to which funds contribute to the RDP.

South Africa's cumulative science budget has had to withstand major changes since 1989 , with defence $R \& D$ spending being the key casualty.

Out of a total current R\&D expenditure of R1,645 million (US\$454 million) - just over half of which is distributed among the seven research councils - R220 million goes to the Department of Defence for military research, with a further R490 million paid as a subsidy to the Atomic Energy Corporation (AEC), for enriching uranium used in South Africa's nuclear weapons.

The remaining money is distributed to the Department of Environmental Affairs' Sea Fisheries Research Institute, the Water Research Commission, the Department of Health's research institutes, various conservation agencies, and to groups carrying out non-nuclear energy research.

In 1989 , by contrast, defence $R \& D$ spending - R1,500 million - took the lion's share of the total R\&D budget. A further R1,000 million went to the AEC. Doubling these sums to make them comparable to 1995 prices indicates the extent of the decline in state spending on R\&D over the past six years as a result of the decline in its military component.

The Witwatersrand meeting's main function was to debate a draft policy suggestion prepared by George Ellis, president of the Royal Society of South Africa (see Nature 371, 94; 1994). Participants split up into groups to discuss specific proposals for physics and chemistry, earth sciences, life sciences, mathematics, and environmental sciences as well as interdisciplinary research.

Within the life sciences, participants agreed on three areas of importance. The first included research on aspects of health, agriculture and the environment which address basic human needs, one of the main themes of the development programme.

Identifying areas of life sciences research which could stimulate growth in the South African economy - the other principal theme of the RDP - proved more challenging. Two suggestions, both related to the country's uniquely-rich biota, were to investigate ways of exploiting indigenous knowledge of naturally-derived medicinal products, and to promote research on biodiversity in order to boost the country's burgeoning efforts in 'eco-tourism'.

Finally, the participants in the life sciences group felt that existing scientific strengths should be built on, regardless of their potential utility.

Michael Cherry

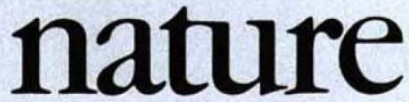

Our new address

is

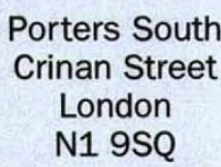

Tel: +44 (0) 1718334000

Fax: +44 (0) $1718434596 / 7$ 